\title{
The Moderating Effects of Self-Efficacy on the Relationship Between Stress and Cigarette Smoking Behavior Among Adolescents in Kerman, Iran
}

\author{
Samira Golestan ${ }^{1} \&$ Haslinda Binti Abdullah ${ }^{2}$ \\ ${ }^{1}$ Faculty of Human Ecology, University Putra Malaysia, E-11-02, The Heritage, Mines Resort City, 43300 Seri \\ Kembangan, Selangor, Malaysia \\ ${ }^{2}$ Institute for Social Science Studies (IPSAS), University Putra Malaysia, UPM Serdang, Selangor 43400, \\ Malaysia \\ Correspondence: Samira Golestan, Faculty of Human Ecology, University Putra Malaysia, E-11-02, The Heritage, \\ Mines Resort City, 43300 Seri Kembangan, Selangor, Malaysia. Tel: 98-913-343-6185 E-mail: \\ samira_golestan@yahoo.com
}

Received: May 13, 2014 Accepted: May 30, 2014 Online Published: September 22, 2014

doi:10.5539/ach.v7n1p130 URL: http://dx.doi.org/10.5539/ach.v7n1p130

\begin{abstract}
This paper aims to examine the relationship between the individual factor of stress and cigarette smoking behavior and also determine the moderating effect of self-efficacy on the relationship between stress and cigarette smoking behavior among adolescents in Kerman, Iran. A quantitative research method was employed. The samples included three hundred current smoker adolescents between the ages of 15 to 18 . The data were collected by means of self-administered questionnaires and then analyzed by AMOS software. The direct structural model was employed to determine the path relationships between the individual factor of stress and cigarette smoking behavior. In addition, a multi-group analysis approach was applied to assess the moderating effect of self-efficacy on the relationship between stress and cigarette smoking behavior among adolescents. The results of testing the structural equation model revealed that there is a positive significant relationship between the individual factor of stress and cigarette smoking behavior. It was also found that self-efficacy significantly moderates the effects of stress on the cigarette smoking behavior among adolescents. The paper proposes some suggestions in order to prevent cigarette smoking behavior among adolescents.
\end{abstract}

Keywords: stress, cigarette smoking behavior, self-efficacy, adolescents

\section{Introduction}

Cigarette smoking has been identified as a major public health problem worldwide (Eftekhari, Nassr, \& Sallehi, 2007; Sarafzade, Boshtam, \& Tafazoli, 2004). Many negative consequences have been attributed to cigarette smoking, which is a major global contributor to death from chronic diseases (Center for Disease Control and Prevention, 2006; Emmeree, 2003; Nichols, 2006). Studies have revealed that a majority of the patients who suffer from lung cancer (87\%) are smokers (Nichols, 2006; Emmeree, 2003). Based on the World Health Organization reports, it is estimated that 5.4 million people die annually because of cigarette smoking. This figure is expected to rise to 10 million by the year 2025 (WHO, 2008). Smoking is the sixth cause of death in the world and if the trend remains the same until 2030, the number of smoking-induced deaths will increase to eight to ten million (WHO, 2008).

Initiation of cigarette smoking occurs almost exclusively during adolescence (Ziaaddini, meymandi, \& Zarezadeh, 2007; Sally, 2009; Poorasl et al., 2011; Poorasl, Fakhari, \& Shamsipour, 2011). Reportedly, more and more adolescents show an increasing tendency to smoking and it has become an ordinary habit among a considerable number of adolescents (Hiemstra et al., 2011; Pouresmlami, 2008). Although cigarette smoking among adults has steadily declined over the past decade, empirical evidence reveals that cigarette smoking among adolescents has risen sharply and now it is a global problem (Diane et al., 2005; Kear, 2002). Center for Disease Control and Prevention (2003) warns that adolescent smoking rates remain unacceptably high. Only in the United States, over five million adolescents are estimated to be cigarette smokers (Centers for Disease Control and Prevention, 2003; Mee, 2009; Nichols, 2006). Studies have identified that the initiation of cigarette smoking habits almost always occurs in high 
schools, suggesting that if adolescents can be kept smoke-free during their high school time, it is more likely that they will never start smoking (Deborah, 2006; U.S. Department of Health and Human Services, 2000).

Many international studies have shown that about 85 to $90 \%$ of heavy smokers start smoking before the age of 20 (Nakhaee, Divsalar, \& Bahreinifar, 2011; Pouresmlami, 2008). More than one-third of those who experienced smoking before the age of 18 will become daily and about two-thirds of them will become regular smokers (Centers for Disease Control and Prevention, 2000; Ramezankhani, Sarbandi, \& Masjedi, 2010; Sally, 2009). Usually with a simple smoking experience (1 or 2 puffs), the adolescent will become regular smokers. Persons of all ages choose to ignore public health warnings related to smoking, but adolescents and young adults have the highest smoking rates. Adolescent cigarette smoking commonly paves the way towards drug use (Mee, 2009; Sally, 2009; Ramezankhani, Sarbandi, \& Masjedi, 2010; Poorasl et al., 2011). In addition to more frequent use of illicit drugs, youths who consistently smoke throughout adolescence are at significantly greater risk of consuming and getting addicted to marijuana, alcohol and other drugs (Guizzetti, 2008; Mark et al., 2006; Ramezankhani, Sarbandi, \& Masjedi, 2010; Vega \& Gil, 2005).

Smoking has been described as an epidemic in developing countries (Rozi, Butt, \& Akhtar, 2007; World Health Organization, 2008). There are about 1.3 billion smokers in the world and approximately $80 \%$ of them live in the developing countries (American Cancer Society, 2006; Rozi et al., 2007). The World Health Organization has reported prevalence of smoking among adolescents in the Eastern Mediterranean as following: 26.6\% in Iran, $20.9 \%$ in Kuwait, $17.2 \%$ in Iraq, 10.1\% in Pakistan and 15.9\% in Saudi Arabia (WHO, 2009).

Among the other developing countries, Iran has one of the youngest population profiles in the world (Ziaaddini et al., 2007; pouresmlami, 2008). Studies in Iran indicated that most people start smoking under the age of 19, during their adolescence (Ramezankhani, Sarbandi, \& Masjedi, 2010). Approximately, 71\% of Iranian smokers reported that their first smoking experience was in their adolescence (Kelishadi, Ardalan, \& Gheiratmand, 2006; Pouresmlami, 2008; Ziaaddini et al., 2007). The high availability and legality of cigarette smoking is the main reason for annually about 50,000 deaths in Iran (Pouresmlami, 2008). Unlike other forms of addiction, such as alcoholism, smoking cigarettes is not outlawed by religious edicts. In Iran, addiction to cigarettes is not considered to be as serious as addiction to drugs (Eftekhari et al., 2007). In contrast to other addictives, cigarettes are more available. Thus, cigarette use among adolescents needs to be taken into account and studied (Mee, 2009; Nakhaee \& Divsalar, 2009; Ramezankhani, Sarbandi, \& Masjedi, 2010; Rigotti et al., 2005).

In the light of the previous findings, stress and self-efficacy as individual factors, are posited to play a role in cigarette smoking behavior (Breslau, Kilbey, \& Andreski, 1999; Hiemstra et al., 2011; Sally, 2009; Savioli, 2005).

Stress is an individual significant risk factor contributing to negative outcomes of adolescents' health. Stress is reported to be related to cigarette smoking behaviors since cigarette smoking is known as a way of coping with stress among adolescents. As smoking is viewed as a stress reliever, adolescents will smoke more to reduce stress (Yaris, 2010; Giesler, 2005; Feldner et al., 2007). Based on the theories and literature, stress has been reported as the best predictor of adolescent smoking behavior (Novy \& Donohue, 1985). In addition, self-efficacy is another individual factor that is significantly associated with cigarette smoking among adolescents, which increases the likelihood of cigarette smoking behavior (Hiemstra et al., 2011). A lot of studies have investigated the direct relationship between self-efficacy and cigarette smoking behavior. But, no research has examined the moderating effects of self-efficacy in the process of stress and cigarette smoking behavior among adolescents. So, in order to fill the research gap, in the present study, the interactive effects of a moderating variable (self-efficacy) with the individual factor of stress influencing on adolescent smoking behavior will be examined in a sample of adolescent smokers'.

The present study was proposed to examine the relationship between individual factors of stress and cigarette smoking behavior and also investigate the moderating effects of self-efficacy on the relationship between stress and cigarette smoking behavior among adolescents in Kerman, Iran.

\section{Methodology}

\subsection{Sample Procedure and Sample Profile}

The study sample comprises adolescents' cigarette smoker between the ages of 15 and 18 years old in high schools in Kerman. Twenty-two schools were selected for the study using a cluster sampling technique (ten schools from Zone One and twelve schools from Zone Two). In order to determine the sample size, G-Power statistical analysis program developed by Erdfelder, Faul and Buchner (1996) was used. After setting the values of .1 for effect size, a power of .95 and alpha .05 , the regression was selected as the data analysis method. The ideal sample size calculated by the software for this method was $n=270$. However, to enhance the accuracy of the findings, 300 
samples were collected. In addition, the sampling method used for the selection of respondents (current cigarette smokers) was convenience sampling.

\subsection{Instrumentation}

Stress Scale: Stress was measured by Perceived Stress Scale (PSS) (Cohen et al., 1983). PSS scale is a ten-item self report questionnaire designed to measure an individual's level of perceived stress in the past month. The questions in the PSS ask about feelings and thoughts during the last month. This Scale rated on a five-point Likert scale, ranging from $(0=$ Never to $4=$ Very Often). Higher scores indicate higher level of perceived stress and vice versa. The reliability assessment of the perceived stress scale in the present study, after removing three items (because of the low values of their internal reliability coefficients), yielded an alpha coefficient of 0.77 .

Self-Efficacy Scale: Self-efficacy was measured by eight items adapted from the Smoking Self-Efficacy Questionnaire (Etter, Bergman, Humair, \& Perneger, 2000). This instrument had a five-point Likert-type scale (Not at all sure (1) to absolutely sure (5)). Higher scores indicated high levels of self-efficacy and vice versa. The internal reliability test of the questionnaire in the present study yielded an alpha coefficient of 0.82 .

Cigarette Smoking Behavior Scale: Cigarette smoking behavior was measured with questions refined from the national high school YRBS questionnaire (Centers for Disease Control and Prevention, 2000). This scale is a 5-item self-report questionnaire designed to measure cigarette smoking behavior and is rated on a seven-point Likert scale. If respondents opt for 'smoked 10-30 days in the past 30 days and less than five cigarettes each day', they are regarded as light current smokers. Additionally, smoking '10-30 days in the past 30' and 'five or more cigarettes each day' means heavy current smoker. Finally, having smoked 1-9 days in the past 30 days means that the respondent is an occasional current smoker. In this research the reliability of the Cigarette Smoking Behavior Scale was 0.77.

\section{Results and Discussion}

\subsection{Descriptive Statistics}

The descriptive analyses of the respondents' demographic background, such as age, gender, level of education, and monthly spending money, is presented in Table 1. This Table shows the frequencies and percentages of respondents' demographic background. The data were collected from 300 adolescent respondents.

The age of the adolescents, as reported by the respondents, ranged from 15 to 18 . Their mean age was 16.5. The Majority of the respondents (53\%) belonged to the age group of $17-18$ year-olds. Regarding gender, $65 \%$ of the adolescents were male and $35 \%$ were female. In terms of education, the largest part of the subjects in this study belonged to the third grade of high school; that comprised $26.7 \%$ of the whole subjects. Table 1 also illustrates that the majority of the respondents' (66.3\%) monthly spending money was between 0-130 thousand Tomans (around \$40).

Table 1. Frequencies and Percentages of Respondents' Demographic Background

\begin{tabular}{|c|c|c|}
\hline Variables & Number $(n=300)$ & Percentage $(\%)$ \\
\hline \multicolumn{3}{|l|}{ Age } \\
\hline 15 years & 69 & 23.0 \\
\hline 16 years & 72 & 24.0 \\
\hline 17 years & 80 & 26.7 \\
\hline 18 years & 79 & 26.3 \\
\hline \multicolumn{3}{|l|}{ Mean $=16.5$} \\
\hline \multicolumn{3}{|l|}{ Level of Education } \\
\hline First grade & 69 & 23.0 \\
\hline Second grade & 72 & 24.0 \\
\hline Third grade & 80 & 26.7 \\
\hline Pre-university & 79 & 26.3 \\
\hline \multicolumn{3}{|l|}{ Gender } \\
\hline Male & 195 & 65.0 \\
\hline Female & 105 & 35.0 \\
\hline \multicolumn{3}{|c|}{ Monthly spending Money (Thousand Toman) } \\
\hline$<130$ & 199 & 66.3 \\
\hline$>130$ & 101 & 33.7 \\
\hline
\end{tabular}




\subsection{The Inferential/Structural Equation Modeling (SEM) Results}

The multivariate technique of Structural Equation Modeling was employed to test the validity of the instrument, based on the collected data and the underlying research hypothesis. In this section, the results are presented in three phases based on the practical step in SEM analyses. The steps include: (i) Individual Confirmatory Factor Analysis for each latent variable, (ii) the measurement model or overall CFA model which comprises the latent variables in the study, and (iii) the structural models to test the research hypotheses based on the research framework of study.

\subsubsection{The Confirmatory Factor Analysis Models}

Prior to the Structural Equation Modeling, it is necessary to confirm convergent validity and construct validity (i.e., the study constructs individually fit the model).

\subsubsection{Stress Individual CFA}

Stress was assessed by 10 items. The individual CFA for stress was specified using the items. The model has been portrayed in Figure 1. The results demonstrate that the model fits the data for this construct, for two reasons: (i) four of the goodness of fit indices fall between a acceptable value and meet the criteria for showing a good fit including GFI $=.962, \mathrm{CFI}=.981, \mathrm{IFI}=.981, \mathrm{TLI}=.972$, and (ii) the other two goodness of fit indices including RMSEA $=.083$ and Relative $\chi 2=3.063$ are too close to their related cutoff point; the cutoff point for RMSEA is the value between 0.03 and 0.08 and cutoff point for relative $\chi^{2}$ is any value less than 3 while less than five is also acceptable according to Ho (2006). Therefore, all goodness of fit indices confirmed a good fit for the stress CFA model.

The next step was to assess the convergent validity of construct through investigation of factor loadings, average variance extracted, and constructs reliability. The indicators of this assessment have been reported in Table 2 . The results regarding standardized factor loadings show that all items exceed the cutoff point of .5 and even as demonstrated in Figure 1, all items have a value above .8 supporting high levels of factor loadings. The average variance of stress construct was .67 which also exceeds the cutoff point of .5. A very high level of construct reliability (.934) was obtained for stress construct. Thus, it could be concluded that the stress construct was measured using valid and reliable items and demonstrate a convergently valid construct.

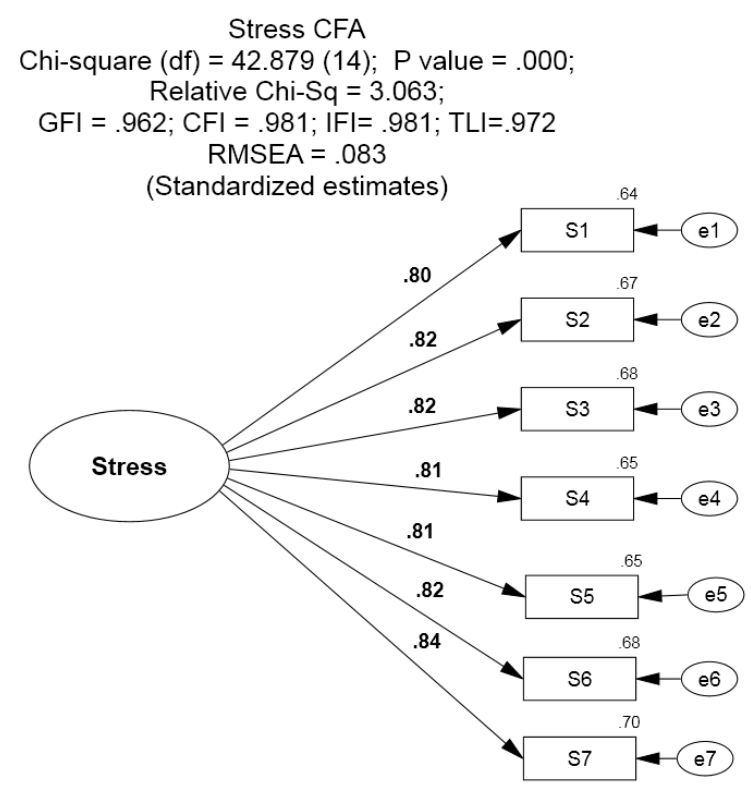

Figure 1. Stress CFA Model 
Table 2. The Result of Stress CFA Model

\begin{tabular}{ccccc}
\hline Variable/dimension & Items & $\begin{array}{c}\text { Standardized } \\
\text { Factor loading }\end{array}$ & $\begin{array}{c}\text { Average Variance Extracted } \\
\text { (AVE) }\end{array}$ & $\begin{array}{c}\text { Construct Reliability } \\
\text { (CR) }\end{array}$ \\
\hline \multirow{5}{*}{ Stress } & S1 & .803 & & \\
& S2 & .821 & & \\
& S3 & .824 & .67 & .934 \\
& S4 & .807 & & \\
& S5 & .809 & & \\
S6 & .822 & & \\
& S7 & .838 & & \\
\hline
\end{tabular}

\subsubsection{Self-Efficacy Individual CFA}

The self-efficacy construct was measured using eight items. Using these items the individual CFA model was specified. The model is shown in Figure 2. The results of model fit assessment for the self-efficacy construct confirmed that the model was fit for the data according to the following goodness of fit indices: Relative $\chi 2=$ $2.772 ; \mathrm{GFI}=.954, \mathrm{CFI}=.973, \mathrm{IFI}=.973, \mathrm{TLI}=.963, \mathrm{RMSEA}=.077$ except chi-Square $(\chi 2(20)=55.440, \mathrm{p}$ $=.000$ ). The reason has been discussed in pervious individual CFA. Consequently, it could be said that goodness of fit indices support a good fit for the model.

Next, the construct was assessed for its convergent validity through factor loadings, average variance extracted, and construct reliability. The results of convergent validity assessment have been reported in Table 3. Based on these results, the standardized factor loadings for the self-efficacy construct range from .697 to .853 , all acceptable values, above the cutoff point of .5. The average variance extracted for the self-efficacy construct was .57, which was satisfactory as was greater than the required value of .5. The construct reliability of the self-efficacy construct was tested and a high value of .91 was achieved which exceeds the acceptable value of .7. Consequently, the convergent validity for the self-efficacy construct was confirmed through assessment of three indicators, including standardized factor loading, average variance extracted, and construct reliability. It could be concluded that the self-efficacy construct in this study was measured through valid and reliable items.

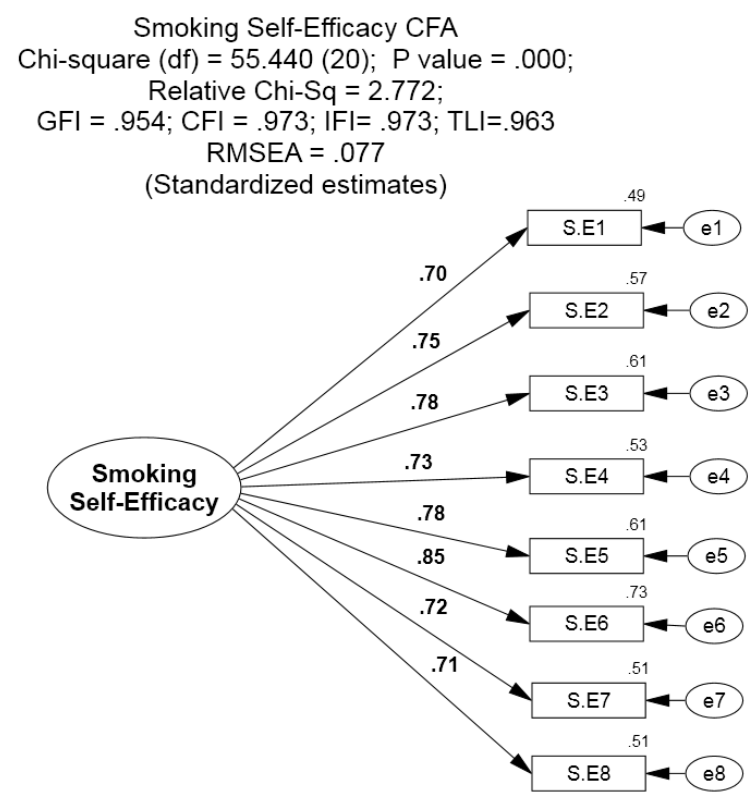

Figure 2. Self-Efficacy CFA Model 
Table 3. The Result of Self-Efficacy CFA Model

\begin{tabular}{lcccc}
\hline Variable/dimension & Items & $\begin{array}{c}\text { Standardized } \\
\text { Factor loading }\end{array}$ & $\begin{array}{c}\text { Average Variance Extracted } \\
\text { (AVE) }\end{array}$ & $\begin{array}{c}\text { Construct Reliability } \\
\text { (CR) }\end{array}$ \\
\hline Self-Efficacy & S.E1 & .697 & .57 & .91 \\
& S.E2 & .752 & & \\
& S.E3 & .780 & & \\
S.E4 & .726 & & \\
S.E5 & .779 & & \\
S.E6 & .853 & & \\
S.E7 & .717 & & \\
S.E8 & .711 & & \\
\hline
\end{tabular}

\subsubsection{The Structural Equation Model}

After specifying the individual CFA and the measurement model of the study (to test the validity of the instrument based on the collected data), the structural model of the study was designed. The direct structural model was employed to answer the objectives and test the hypothesized path relationships between the variables based on the conceptual research framework.

$\mathrm{H}_{\mathrm{A} 1}$ : There is a positive relationship between individual factor of stress and cigarette smoking behavior.

The result showed that there is a positive significant relationship between the individual factor of stress and cigarette smoking behavior $(\beta=.120, C . R=3.637, \mathrm{P}=.000)$ (Table 4). Therefore, the hypothesized path relation between individual factor of stress and cigarette smoking behavior was supported in this study. It indicates that stress is associated with cigarette smoking behavior.

Table 4. Regression Weights based on the Structural Model

\begin{tabular}{llccccc}
\hline Path Hypothesis & Estimate & S.E. & $\begin{array}{c}\text { Standardized } \\
\text { Regression Weights }\end{array}$ & C.R. & P \\
\hline Stress $\rightarrow \quad$ & $\begin{array}{l}\text { Cigarette Smoking } \\
\text { Behavior }\end{array}$ & .304 & .084 & .120 & 3.637 & .000 \\
& & & & & \\
\hline
\end{tabular}

\subsubsection{Test of the Moderating Hypothesis (Self-Efficacy)}

As presented in the above section for individual CFAs in this study self-efficacy was measured through 8 items as a latent variable. Therefore, in order to test the moderating effects of self-efficacy it was necessary to recode and categorize this variable in two levels including low and high self-efficacy respondent. Thus, the data elicited by the first eight items (as all of them were validated based on CFA model for this variable) were analyzed; the mean was calculated, and finally based on the mean scores the respondents were divided in two groups.

In order to test moderating effects of self-efficacy as the main objective of this study on the path relation between the variables the advanced technique of multi-group Structural Equation Modeling analysis was employed. The multi-group analyses technique was followed by using AMOS software. The system produced two variant/unconstrained and invariant/equal group models (Hair et al., 2006, 2010). According to the unconstrained group model, different regression weights were estimated for low and high self-efficacy respondents, whereas based on the invariant group model it was estimated that the path relationships of interest would be constrained to be equal among respondents with low and high self-efficacy.

$\mathrm{H}_{\mathrm{A} 2}$ : Moderating effects of self-efficacy on the path relationships between the individual factor of stress and cigarette smoking behavior

The results showed that self-efficacy moderates the path relation between stress, as an individual factor, and cigarette smoking behavior since the path relations between stress and cigarette smoking behavior for respondents with low self-efficacy was significant $(\beta=.151, C . R=4.197, P=.000)$. Still it was not significant for those 
respondents with high self-efficacy $(\beta=.085, \mathrm{C} . \mathrm{R}=1.174, \mathrm{P}=.240)$. Therefore, the moderating effect of self-efficacy is supported on this path (Table 5 and 6 ).

Table 5. Regression Weights based on Unconstrained Structural Model for Low Self-efficacy Respondent

\begin{tabular}{llllcll}
\hline Path hypothesis & & Estimate & S.E. & $\begin{array}{l}\text { Standardized } \\
\text { Regression Weights }\end{array}$ & C.R. & P \\
\hline Stress $\rightarrow$ & $\begin{array}{l}\text { Cigarette Smoking } \\
\text { Behavior }\end{array}$ & .370 & .088 & .151 & 4.197 & .000 \\
\hline
\end{tabular}

Table 6. Regression Weights based on Unconstrained Structural Model for High Self-efficacy Respondent

\begin{tabular}{llllccc}
\hline Path hypothesis & & Estimate & S.E. & $\begin{array}{c}\text { Standardized } \\
\text { Regression Weights }\end{array}$ & C.R. & P \\
\hline Stress $\rightarrow$ & $\begin{array}{l}\text { Cigarette Smoking } \\
\text { Behavior }\end{array}$ & .185 & .158 & .085 & 1.174 & .240 \\
\hline
\end{tabular}

\section{Discussion}

This study focused on the role of the individual factor of stress and cigarette smoking behavior, and examined the moderating effect of self-efficacy on the relationship between stress and cigarette smoking behavior among adolescents in Kerman.

The results showed that cigarette smoking was associated with the individual factor of stress, indicating that an increased level of stress significantly raises the risk of cigarette smoking behavior among adolescents. The present finding supported the earlier studies done by Booker et al. (2007), Fields et al. (2009), Yaris (2010) and Slopen et al. (2013) who found positive relationships between stress and cigarette smoking behavior and stressed that higher levels of stress would increase the risk of cigarette smoking in adolescents. These results also supported, the social cognitive theory introducing adolescence as a problematic period of heightened stress in life. It was also found that stress has direct influence on behavioral changes and is a significant risk factor that contributes to negative consequences for health and development in the adolescence (Bandura, 1986).

Smoking as a risky behavior often occurs after stressful events or in stressful situations. A recent review of smoking motives estimates that $80 \%$ of adolescents as well as adult smokers smoke cigarettes when feeling stressed or worried (Parrott, 1992; Wilson, 1997). In fact, smoking has been cited as a means of dealing with stress among young smokers as well as among adults (Savioli, 2005). Research suggests that smoking does nothing to relieve stress and can only contribute to it (Parrott, 1999). Moreover, an adolescent, who has learned that smoking is a method of coping with stress, will develop positive schemas about smoking, which will make it easier for the adolescent to smoke or attempt to smoke (Bektas, Ozturk, \& Armstrong, 2010; Cote, Godin, \& Gagne, 2004; Harakeh, Scholte, \& Vermulst, 2004; Martin \& Bush, 2000; Sussman, 2005).

Self-efficacy is another individual factor that is significantly associated with cigarette smoking among adolescents, which increases the likelihood of cigarette smoking behavior (Hiemstra et al., 2011). Self-efficacy is one of the important aspects of social cognitive theory of Bandura. Bandura explains that self-efficacy "refers to beliefs in one's capabilities to organize and execute the courses of action required to manage prospective situations" (Bandura, 1995; P.2). Research has demonstrated that the effects of self-efficacy on behavior are pervasive (Ando \& Asakura, 2007; Bandura \& Adams, 1977; Barling \& Beattie, 1983). Self-efficacy has been found to be a relevant predictor of susceptibility and also is negatively associated with vulnerability in adolescents (Fagan et al., 2003). Those low in self-efficacy are more likely to be susceptible than those high in self-efficacy (Epstein, Williams, Botvin, Diaz, \& Ifill-Williams, 1999; Harrell, Bangdiwala, Deng, Webb, \& Bradley, 1998; Laborde, 2007).

Researchers stress that self-efficacy influences the problematic behaviors like cigarette smoking (Diane et al., 2005; Fagan et al., 2003; Hiemstra, Otton, De Leeuw, Schayck, \& Engels, 2011; Von, Ebert, Ngamvitroj, Park, \& kang, 2005). They suggest that cigarette smoking behavior is significantly associated with the level of self-efficacy. The outcomes of a number of studies revealed that those who smoked more cigarettes had lower self-efficacy scores and were less confident in their ability to avoid smoking than those who smoked less (Ehrhart, 2005; Fagan et al., 2003; Sterling et al., 2007). 
A wealth of studies examined the direct relationship between self-efficacy and cigarette smoking behavior. This was the first study that examined the moderating effects of self-efficacy in the process of stress and cigarette smoking behavior among adolescents. The findings regarding the moderating effect of self-efficacy showed that self-efficacy moderated the relationship between stress and cigarette smoking behavior.

From this finding, the important role of self-efficacy on the rate of cigarette smoking behavior becomes more obvious. Having a high level of self-efficacy is effective in controlling negative behaviors like cigarette smoking. In fact, adolescents with a high level of self-efficacy are able to cope with problems in a better way and are less likely to display negative behaviors such as smoking. They are less likely to smoke than adolescents with a low level of self-efficacy.

\section{Conclusion and Implication}

The findings of the present study confirm that stress is linked with cigarette smoking behavior among adolescents in Kerman, Iran. These findings reveal that stress plays a significant role in cigarette smoking behavior among adolescents. Therefore, there is the need that educators provide programs that teach adolescents how to cope with stress and also their stress management and problem solving skills, by focusing specifically on what adolescents worry about. The results also proved the moderating effect of self-efficacy on the relationship between stress and cigarette smoking behavior among adolescents. The results showed that there was a stronger impact of stress on cigarette smoking behavior in adolescents with low self-efficacy than in those with high self-efficacy. This implies that adolescents with higher self-efficacy are less likely to be affected by stress and to start negative behavior such as cigarette smoking. Therefore, having a high level of self-efficacy is effective in controlling negative behaviors like smoking. This makes the implications for educators even more obvious, given the important role of self-efficacy in the rate of cigarette smoking behavior among adolescents.

Therefore, it is important that educators provide programmes to enhance self-efficacy. Prevention programs focusing on self-efficacy may be effective ways for reducing the frequency, initiation and amount of cigarette smoking among adolescents. Prevention programs can have remarkable effect on adolescents' confidence and their abilities to say no. Such programs can also help adolescents observe positive social outcomes from refusing to smoke.

It is suggested that effective smoking prevention programs for adolescents should include strategies to enhance self-efficacy. These strategies should include social skills initiatives such as understanding one's emotions-anger control, determining one's positive and negative aspects, learning how to cope with problems, being able to say no, problem-solving, time management and defending one's rights. Also, improving adolescents' self-efficacy through training programs can help adolescents cope more effectively with stress in their lives, particularly when stressful situations are difficult to control.

It is also important that policy makers take action to deter cigarette smoking behavior and also provide and develop more programs to equip adolescents as well as their families with proper skills and knowledge about cigarette smoking behavior; the education should also cover self-health and refusal skills.

To prevent or to decrease the rate of cigarette smoking behavior among adolescents, all the involved social sectors should focus on the enhancement of students' self-efficacy and provide skills on parenting training, social resistance and stress management, in order to enforce the family policies on cigarette smoking behavior. For this, school and family educators and initiatives in the managerial and policymaking levels should be geared towards strengthening the above-mentioned characteristics.

\section{References}

American Cancer Society. (2006). Global smoking epidemic. Retrieved 28 February, 2006, from http://www.cancer.org.

Ando, M., \& Asakura, T. (2007). Psychosocial factors associated with smoking and drinking among Japanese early adolescent boys and girls: Cross-sectional study. BioPsychoSocial Medicine, 1(13), 1-10. www.ncbi.nlm.nih.gov/pmc/articles/PMC1934913.

Bandura, A. (1986). Social foundations of thought and action. Englewood Cliffs: Prentice Hall.

Bandura, A. (1995). Exercise of personal and collective efficacy in changing societies. New York: Cambridge University Press.

Bandura, A., \& Adams, N. (1977). Analysis of self-efficacy theory of behavioral change. Cognitive Therapy and Research, 1, 287-310. 
Barling, J., \& Beattie, R. (1983). Self-efficacy beliefs and sales performance. Journal of Organizational Behavior Management, 5, 41-51.

Bektas, M., Ozturk, C., \& Armstrong, M. (2010). An approach to children's smoking behaviors using social cognitive learning theory. Asian Pacific Journal of Cancer Prevention, 11, 1143-1149.

Booker, C., Unger, J., Azen, S., Lickel, B., \& Johnson, A. (2007). Stressful life events and smoking behaviors in Chinese adolescents: A longitudinal analysis. Nicotine \& Tobacco Research, 9(11), 1085-1094.

Breslau, N., \& Peterson, E. L. (1996). Smoking cessation in young adults: Age at initiation of cigarette smoking and other suspected influences. American Journal of Public Health, 86(2), 214-220.

Centers for Disease Control and Prevention. (2000). Selected cigarette smoking initiation and quitting behaviors among high school students, Mortal Wkly Rep MMWR Morb. United States.

Centers for Disease Control and Prevention. (2003). Tobacco use among middle and high school students (No. Morbidity and Mortality Weekly Report, 1096-1098). United States.

Centers for Disease Control and Prevention. (2006). Cigarette use among high school students (Vol. 55). United States, 1991-2005: MMWR.

Cohen, S., Kamarck, T., \& Memslstein, R. (1983). A global measure of perceived stress. J Health Soc Beh., 24, 385-396.

Cote, F., Godin, G., \& Gagne, C. (2004). Identification of factor promoting abstinence from smoking in a cohort of elemantary school children. Prev Med, 39, 695-703.

Deborah, S. (2006). Predictors of cigarette smoking in adolescents with Asthma. PhD Thesis, Ohio University.

Diane, V., Ebert, S., \& Ngamvitroj, A. (2005). Factors related to cigarette smoking initiation and use among college students. Tobbaco Induced Diseases, 3, 27-40.

Eftekhari, M., Nassr, M., \& Sallehi, M. (2007). Prevalence of cigarette smoking in Tehran: A household study. Iranian Journal of Psychiatry and Behavioral Sciences, 1, 33-37.

Ehrhart, I. (2005). Alcohol expectancies and self-efficacy as moderators of social anxiety and alcohol use among college students. Virginia Polytechnic Institute and State University.

Emmeree, F. (2003). Social factors of cigarette smoking initiation among undergraduate college students. $\mathrm{PhD}$ Thesis, University of Florida, United States

Epstein, J., Williams, C., Botvin, G., Diaz, T., \& Ifill-Williams, M. (1999). Psychosocial predictors of cigarette smoking among adolescents living in public housing developments. Tobacco Control, 8, 45-52.

Erdfelder, E., Faul, F., \& Buchner, A. (1996). G-power: A general power analysis program. Behavior Research Methods, Instruments \& Computers, 28(1), 1-11.

Etter, J., Bergman, M., Humair, J., \& Perneger, T. (2000). Development and validation of a scale measuring self-efficacy of current and former smokers. Addiction, 95, 901-913. www.ncbi.nlm.nih.gov/pubmed/10946439.

Fagan, P., Eisenberg, M., Frazier, L., Stooddard, A., Avrunin, J., \& Sorensen, G. (2003). Employed adolescents and beliefs about self-efficacy to avoid smoking. Addictive Behaviors, 28(4), 613-626.

Feldner, M., Babson, K., Zvolensky, M., \& Vujonavic, A. (2007). Posttraumatic stress symptoms and smoking to reduce negative affect: An investigation of trauma-exposed daily smokers. Addictive Behaviors, 32, 214-227. www.mdlinx.com/emergency-medicine/print.cfm/1749841.

Fields, S., Leraas, K., Collins, C., \& Reynolds, B. (2009). Delay discounting as a mediator of the relationship between perceived stress and cigarette smoking status in adolescents. Behav Pharmacol, 20(5), 455-460.

Giesler, J. (2005). An Examination of Smoking-Related Behaviours and Self-Perceptions, and the Role of School Connectedness in Predicting Cigarette Use Among Students at an Ontario University. University of Waterloo, Ontario, Canada.

Guizzetti, L. (2008). College student alcohol use: Using current research to guide practice. PhD Thesis, University of Pittsburgh, Pennsylvania.

Hair, J. F., Black, W. C., Babin, B. J., Anderson, R. E., \& Tatham, R. L. (2006). Multivariate data analysis (6th ed.). Upper Saddle river NJ: Prentice Hall. 
Hair, J., Black, J., Babin, B., \& Anderson, R. (2010). Multivariate data analysis (7th ed.). New Jersey: Practice Hall.

Harakeh, Z., Scholte, R., \& Vermulst, A. (2004). Parental factors and adolescents' smoking behaviours: An extension of the theory of planed behaviour. Prev Med, 39, 951-961. Retrieved from http://www.sciencedirect.com/science/article/pii/S0091743504001951.

Harrell, J., Bangdiwala, S., Deng, S., Webb, J., \& Bradley, C. (1998). Smoking initiation in youth: The roles of gender, race, socioeconomics, and developmental status. Journal of Adolescent Health, 23, 271-279.

Hiemstra, M., Otton, R., De Leeuw, R., Schayck, O., \& Engels, R. (2011). The Changing Role of Self-Efficacy in Adolescent Smoking Initiation: A 4-Year Longitudinal Study. Journal of adolescent health, 47(6), 597-603.

Ho, S., Kei Mak, K., \& Day, J. (2012). Smoking of parents and best friend: independent and combined effects on adolescent smoking and intention to initiate and quit smoking. Nicotine \& Tobacco Research, 17, 1-8.

Kear, M. E. (2002). Psychosocial determinants of cigarette smoking among college students. Journal of Community Health Nursing, 19(4), 245-257.

Kelishadi, R., Ardalan, G., \& Gheiratmand, R. (2006). Smoking behavior and its influencing factors in a national-representative sample of Iranian adolescents. Prevention Medicine, 42(6), 423-426.

Laborde, J. (2007). Developing a hierarchy of the adolescent susceptibility construct that can be used in health communication campaigns to target adolescents at risk. The Florida State University. Addiction, 100, 1358-1369.

Mark, G., Myers, P., \& Kelly, H. (2006). Cigarette smoking among adolescents with alcohol and other drug use problems. Addictive, 29, 35-45. Retrieved from http://pubs.niaaa.nih.gov/publications/arh293/221-227.

Martin, C., \& Bush, A. (2000). Do role models influence teenager's purchase intentions and behavior?. Consumer Marketing Journal, 17, 441-454.

Mee, S. (2009). Correlates of Smoking Behavior among older Adolescents. The State University of New Jersey, Newark, New Jersey.

Nakhaee, N., \& Divsalar, K. (2009). Prevalence of and Factors Associated With Cigarette Smoking Among University Students: A Study From Iran. Asia-Pacific Journal of Public Health, 76, 34-38.

Nakhaee, N., Divsalar, K., \& Bahreinifar, S. (2011). Prevalence of and Factors Associated With Cigarette Smoking Among University Students: A Study From Iran. Journal of Public Health, 2(1), 32-37.

Nichols, A. (2006). The influence of a school-based substance abuse prevention program reducing smoking among sixth grade African American students in Louisiana. University of California, Los Angeles.

Novy, D., \& Donohue, S. (1985). The relationship between adolescent life stress events and delinquent conduct including conduct indicating a need for supervision. Journal of Adolesence, 20(78), 312-321. http://eric.ed.gov/?id=EJ323321.

Parrott, A. (1992). Smoking and Smoking Cessation: Effects upon Human Performance. Journal of Smoking related Disorders, 3(1), 43-53.

Parrott, A. (1999). Does Cigarette Smoking Cause Stress? American Psychologist, 54, 817-820.

Poorasl, A., Fakhari, A., \& Shamsipour, M. (2011). Transitions between the stages of smoking in Iranian adolescents. Science Direct, 52, 136-138. www.sciencedirect.com/science/article/pii/S0091743510004810.

Pouresmlami, M. (2008). Assessment of Beliefs about Cigaratte Smoking in Middle School in Tehran. University of Medical Sciences, Iran.

Ramezankhani, A., Sarbandi, F., Zarghi, A., Masjedi, M., \& Heydari, G. (2010). Smoking Habits of Adolescent Students in Tehran. Tanaffos Journal, 9(2), 33-42.

Rigotti, N., Moran, S., \& Wechsler, H. (2005). US college students' exposure to tobacco promotions: Prevalence and association with tobacco use. Am J Public Health, 95, 138-144.

Rozi, S., Butt, Z., \& Akhtar, S. (2007). Demographic influences associated with current smoking status of collage students in Karachi, Pkistan. BMC Public Health, 7, 312-320.

Sally, M. (2009). Depression, Mood Variability, and Smoking in Adolescence: A Prospective Analysis. University of Illinois at Chicago, Chicago. 
Sarafzade, N., Boshtam, M., \& Tafazoli, F. (2004). Tobacco use among Iranian men, women and adolescents. European Journal of Pubmic Health, 14, 76-78.

Savioli, W. (2005). The relationship between perceived stress and smoking. Youngstown State University.

Slopen, N., Kontos, E., \& Ryff, C. (2013). Psychosocial stress and cigarette smoking persistence, cessation, and relapse over 9-10 years: A prospective study of middle-aged adults in the United States. Cancer Causes Control Journal, 24(10), 1849-1863.

Sterling, K., Diamond, P., Mullen, P., Pallonen, U., Ford, K., \& McAlister, A. (2007). Smoking-related self-efficacy, beliefs, and intention: assessing factorial validity and structural relationships in 9th-12th grade current smokers in Texas. Journal of Addictive Behaviors, 32, 1863-1876.

Sussman, S. (2005). Risk factors and prevention of tobacco use. Pediatr Blood Cancer, 44, 614-619.

United States Department of Health and Human Services (2000). Preventing Tobacco Use Among Young People: A Report of the Surgeon General. Atlanta, GA: U.S. Department of Health and Human Services, Public Health Service, Centers for Disease Control and Prevention. National Center for Chronic Disease Prevention and Health Promotion, Office on Smoking and Health.

Vega, W., \& Gil, A. (2005). Revisiting drug progression: Long-range effects of early tobacco use.

Von, D., Ebert, S., Ngamvitroj, A., Park, N., \& kang, D. (2005). Factors Related to Cigarette Smoking Initiation and Use among College Students. Tobbaco Induced Disease, 1, 27-40.

Wilson, K. (1997). Stress Managment among Adolescents: Smoking, Exercise, Snacking, and Listening to Music as Responses to Environmental Stressors and Moderators of Negative Affect. Eastern Michigan University, Michigan.

World Health Organization (2009). Adolescent Health and Development, from http://www.searo.who.int/en/ Section13/Section1245 4980.htm

World Health Organization, (2008). Tobacco key facts. Retrieved 11 May, 2008, from http://www.who/int/topics/tobacco/facts/en/index.html

Yaris, S. (2010). The mediating role of Meta cognition on the relationship among depression/anxiety/negative impact of life experience and smoking dependence. Turkish.

Ziaaddini, M., Meymandi, M., \& Zarezadeh, A. (2007). The prevalence and motivation of cigarette smoking among Kerman high school students. Iranian Journal of Psychiatry, 2, 41-45. http://ijps.tums.ac.ir/index.php/ijps/article/viewFile/234/229

\section{Copyrights}

Copyright for this article is retained by the author(s), with first publication rights granted to the journal.

This is an open-access article distributed under the terms and conditions of the Creative Commons Attribution license (http://creativecommons.org/licenses/by/3.0/). 